Portland State University

PDXScholar

Engineering and Technology Management

Faculty Publications and Presentations

$11-2010$

\title{
A Look into the Future of Wireless Mobile Communication Technologies
}

Jisun Kim

Portland State University

Tugrul Unsal Daim

Portland State University, tugrul@etm.pdx.edu

Timothy R. Anderson

Portland State University, tim.anderson@pdx.edu

Follow this and additional works at: https://pdxscholar.library.pdx.edu/etm_fac

Part of the Operations Research, Systems Engineering and Industrial Engineering Commons Let us know how access to this document benefits you.

\section{Citation Details}

Kim, Jisun; Daim, Tugrul; and Anderson, Timothy R., "A Look into the Future of Wireless Mobile Communication Technologies" (2010). Engineering and Technology Management Faculty Publications and Presentations. Paper 42. http://archives.pdx.edu/ds/psu/9646

This Post-Print is brought to you for free and open access. It has been accepted for inclusion in Engineering and Technology Management Faculty Publications and Presentations by an authorized administrator of PDXScholar. Please contact us if we can make this document more accessible: pdxscholar@pdx.edu. 


\section{A look into the future of wireless mobile communication technologies}

Jisun Kim, Tugrul Daim ${ }^{1}$ and Tim Anderson

Department of Engineering and Technology Management, Portland State University, OR 97201, U.S.A.

The number of wireless mobile communication service subscribers has reached 4.6 billion worldwide in 2009, and mobile revenues are expected to be over \$1 trillion around 2012 according to the International Telecommunication Union (ITU) (ITU, 2010). A significant number of studies have been done to forecast the growing market and evaluate the new generation technology, the Beyond 3 Generation (B3G). However, there is no study forecasting when any of these new technologies will be commercialized. This paper presents a technical framework for forecasting the commercialization timeline of B3G technologies and provides insight on technology trajectories from $1 \mathrm{G}$ to $4 \mathrm{G}$. The results show that a combination of technical parameters can explain heterogeneous wireless mobile communication technologies. Three parameters selected include channel bandwidth, channel bit rate, and data capacity for technical framework.

Keywords: Technology Forecasting, Wireless Mobile Communication Technologies, Multiple Regression Analysis

\section{Introduction}

Wireless mobile communication is one of the rapidly growing industries (Du Preez and Pistorius, 2003). Since the first mobile phone, Advanced Mobile Phone Service (AMPS), commercialized in Japan in 1979 (Smith and Collins, 2007), the number of subscribers worldwide exceeded 1 billion in 2002 (Minomo and Masamura, 2004). ITU(2010) forecasted it will grow to approximately 5 billion in 2010. OECD reports that the revenue in the worldwide mobile telecommunication market in 2007 was $\$ 493$ billion (Figure 1).

\footnotetext{
${ }^{1}$ Corresponding author. Email: tugrul@etm.pdx.edu
} 


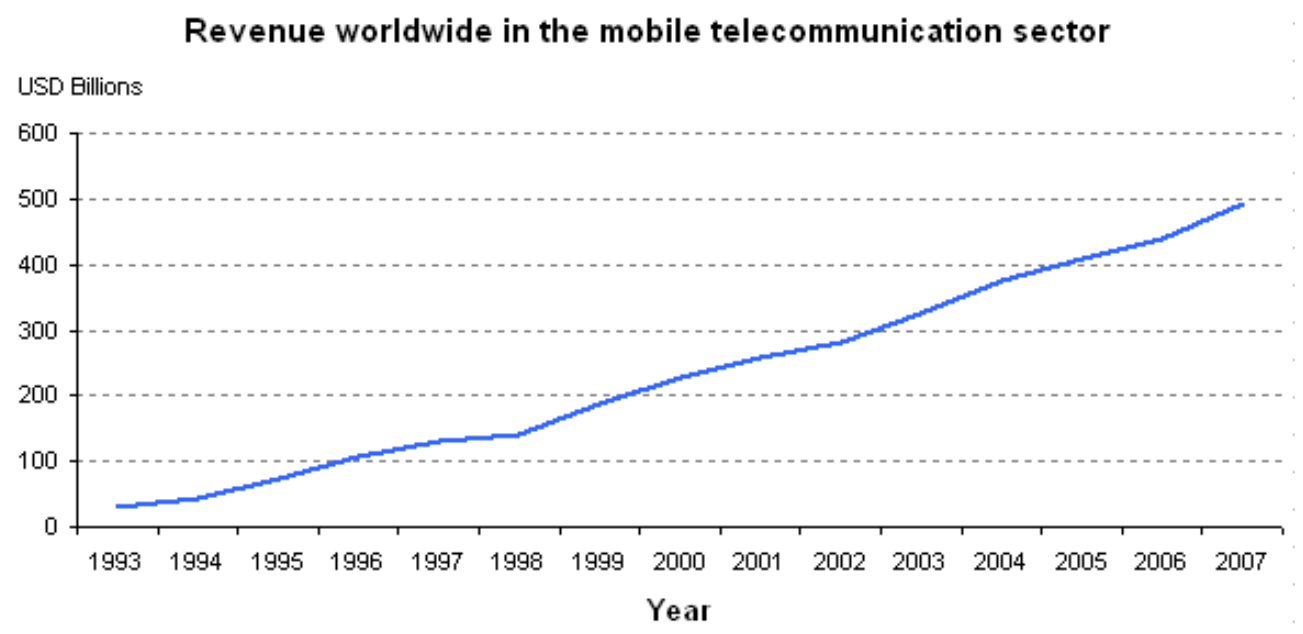

Figure 1 Revenue worldwide, Source: OECD Key ICT Indicators (OECD, 2009)

The third generation of wireless mobile communication started with CDMA2000 EV/DO in 2001. However, 3G licenses worldwide have been delayed due to the heavy investment requirements for new 3G infrastructure as well as lack of attractive applications (Ryu et al., 2004; Park et al., 2006). Wireless mobile telecommunication equipment and services can be rapidly developed, but developing infrastructure requires heavy investment and hence a longrange strategic plan over a timeframe of 10 years (Flament et al., 1999). Technology forecasting helps to overcome the inherent uncertainty of research and development (R\&D) activity in two ways: one is to set a R\&D goal and the other is to identify opportunities by exploring technical characteristics in the future (Martino, 1993).

There is much related research on exploring technologies required for both 3G and beyond 3G. They can be grouped under three major streams:

1) Forecasting subscription and market growth with diffusion or extrapolation models (Kim et al., 1999; Kumar et al., 2002; Venkatesan and Kumar, 2002; Frank, 2004; Wenrong et al., 2006; Yoo and Moon, 2006; Madden and Tan, 2007)

2) Foresight exercises with experts for development of a vision for the future of the wireless mobile communication technologies and related social needs. (Hanson and Ramani, 1988; Evci, 1994; Smyth et al., 1995; Dasilva et al., 1997; Mohr and Becher, 2000; Ohmori et al., 2000; Bi and Zysman, 2001; Sun et al., 2001; Gazis et al., 2002; Evci et al., 2003; Hu and Lu, 2003; Park et al., 2006) 
3) Scenario analysis on future wireless mobile communication technologies and their impacts on society (Flament et al., 1999; Ryu et al., 2004)

None of these studies attempted to forecast when and what kind of a future technology will be feasible with any quantitative forecasting method. Future trajectory of key technical parameters and performance of wireless mobile communication technologies can provide a window of feasible future technology and, therefore, help us to develop a more reliable and robust strategy. So, our major objective is to explore if we can come up with a framework to explain the evolution of wireless mobile communication technologies.

In order to answer this question, this paper utilizes the following steps: 1) define technology structure and parameters, 2) describe foreseeable technologies, 3) model the evolution of these technologies 4) forecast the expected year of commercialization of B3G technologies, and 5) provide and discuss a trajectory of future wireless mobile communication technologies.

\section{Wireless Mobile Communication Technologies}

In the early 1980s, the first generation (1G) of wireless mobile communication technologies included the Advanced Mobile Phone System (AMPS) introduced in the United States, Total Access Communication System (TACS) in the United Kindom, Nordic Mobile Telephone (NMT) system in the Scandinavian countires, C450 in Germany and Nippon Telephone \& Telegraph (NTT) in Japan (Garg and Wilkes, 1996). These techologies used analog frequency modulation (FM) for speech transmission and frequency shift keying (FSK) for signaling (Padgett et al., 1995). The critical problems of the first generation (1G) included capacity bottlenecks and incompatible standards.

Therefore, the second generation was developed to provide higher capacity and a continental system with full international roaming and handoff (Goodman, 1991). This generation, including Global System for Mobile Communications (GSM), IS-136 (time-division multiple access, TDMA), IS-95 (code-division multiple access, CDMA), and Personal Digital Cellular (PDC), significantly reduced the cost of handset and supporting infrastructure systems (Bi and Zysman, 2001). The second and a half generation (2.5G) is the interim platform to bridge the $2 \mathrm{G}$ systems into the 3G by bringing the internet into wireless mobile communication (Sun et al., 2001). WiDEN, GPRS and EDGE are systems in this generation. However, these techologies are still 
optimized for voice service, and not for proper data communication (Smith and Collins, 2007).

The third generation (3G) now is being deployed and it improves the spectral efficiency, cost of the system, and data/multimeida capacity (Bi and Zysman, 2001). CDMA2000 EV/DO, WCDMA (UMTS), TD-CDMA, and TD-SCDMA are technology platforms developed for 3G. Througout three generations, wireless mobile communication operators have been selecting and investing in a path to transition into 3G (Smith and Collins, 2007). Wireless mobile communication technologies ranging from $1 \mathrm{G}$ to $3 \mathrm{G}$ are summarized in Table 1.

Table 1 1G, 2G, 2.5G, and 3G technologies

\begin{tabular}{|c|c|c|c|c|}
\hline Generation & $1 G$ & $2 \mathrm{G}$ & $2.5 \mathrm{G}$ and $2.7 \mathrm{G}$ & $3 G$ \\
\hline Systems & $\begin{array}{l}\text { NTT, NMT-450, NMT- } \\
\text { 900, C450, AMPS, } \\
\text { TACS, NAMPS }\end{array}$ & $\begin{array}{l}\text { CT2, IS-54, PDC, } \\
\text { CDMA one, GSM } \\
\text { 900, JDC, GSM1800, } \\
\text { iDEN } \\
\end{array}$ & $\begin{array}{l}\text { WiDEN, HSCSD, } \\
\text { cdma2000, GPRS, } \\
\text { EDGE }\end{array}$ & $\begin{array}{l}\text { WCDMA (UMTS), } \\
\text { TD-CDMA, TD- } \\
\text { SCDMA, CDMA2000 } \\
\text { DO/EV, HSDPA }\end{array}$ \\
\hline $\begin{array}{c}\text { Year of first } \\
\text { adoption }\end{array}$ & $\begin{array}{c}1979 \\
(\mathrm{NTT})\end{array}$ & $\begin{array}{c}1990 \\
\text { (D-AMPS) }\end{array}$ & $\begin{array}{c}2001 \\
(\mathrm{cdma} 2000)\end{array}$ & $\begin{array}{c}2002 \\
(\mathrm{CDMA} 2000 \mathrm{EV} / \mathrm{DO})\end{array}$ \\
\hline $\begin{array}{l}\text { Country of } \\
\text { first adoption }\end{array}$ & Japan & U.S. & Korea & Korea \\
\hline $\begin{array}{l}\text { Technical } \\
\text { Issues }\end{array}$ & $\begin{array}{l}\text { Introducing cellular } \\
\text { approach (frequency } \\
\text { reuse, handoff, central } \\
\text { control) }\end{array}$ & $\begin{array}{l}\text { Increasing system } \\
\text { capacity up to } 3 \text { times } \\
\text { over } 1 G \text {, improving } \\
\text { security }\end{array}$ & $\begin{array}{l}\text { Utilizing existing } \\
\text { infrastructure, } \\
\text { introducing packet } \\
\text { data service }\end{array}$ & $\begin{array}{l}\text { Improve spectra } \\
\text { efficiency by using } \\
\text { smaller cells, } \\
\text { providing high quality, } \\
\text { multimedia service } \\
\text { and global standard } \\
\end{array}$ \\
\hline Service & Voice, Mono-service & $\begin{array}{l}\text { Voice, SMS, Mono- } \\
\text { media }\end{array}$ & Data service & $\begin{array}{l}\text { Voice, Data, } \\
\text { Multimedia }\end{array}$ \\
\hline
\end{tabular}

Source: Garg and Wilkes (1996), Gibson(1996), Sun (2001) and Gruber (2005)

The third generation systems may not be sufficient to fulfill the explosively increasing traffic in 2010. The fourth generation will be required to cover at least 10 times the capacity available in 3G (Ohmori et al., 2000). Numerous research studies provide a vision for expected technical capacity of the Beyond 3 Generation (3G) or the fourth generation (Ohmori et al., 2000; Jorguseski et al., 2001; Sun et al., 2001; Evci et al., 2003; Hu and Lu, 2003; Ryu et al., 2004; Seungwan et al., 2005; Dongchun et al., 2006). ITU-R, a standards body subcommittee of the International Telecommunication Union (ITU) relating to radio communication, proposed a concept for the Beyond $3^{\text {rd }}$ Generation: a high data rate, a low cost, use of IPv6, portability of numbers, and integration of wired and wireless communications (Ryu et al., 2004). 
Table 2 4G Visions Summary (modified from Sun et al., 2001)

\begin{tabular}{|l|l|}
\hline \multicolumn{1}{|c|}{ Property } & \multicolumn{1}{|c|}{ 4G } \\
\hline Starting time & 2010-2012 \\
Driven technique & Intelligent software, Auto configuration \\
Representative standard & OFDM, UWB \\
Radio frequency & $3 \mathrm{GHz}-5 \mathrm{GHz}$ \\
Data capacity & $10 \mathrm{Mbps}-20 \mathrm{Mbps}$ \\
Multi-access technologies & FDMA, TDMA, CDMA \\
Service type & Multimedia, Machine to Machine \\
\hline
\end{tabular}

\section{Research Framework}

This section will describe the technology framework used to characterize the wireless technologies. Data collection and analysis methods will also be described.

The four technical parameters defined in the technology framework section have trade-offs among them. More channel bandwidth allows a system to produce more throughputs such as data capacity while reducing the number of channels within the allocated spectrum. The reduced channels, hence, reduce the overall number of calls available. The long-term trend is to increase data capacity by compensating the number of channels. Therefore, technology has been developed to improve the efficiency so that more users can have access to more data in a given spectrum allocation.

A composite measure of a technology is required if there are possibility of trade-offs among technical parameters (Martino, 1993). A designer will decide which parameters should be emphasized and which will be sacrificed for a specific application of a technology or device. Therefore, several devices or technologies in the same generation may have different values for the various parameters. Wireless communication technologies are characterized as heterogeneous for this reason.

Alexander and Nelson (1973) defined a composite measures of technical parameters as "technology frontier" in the N-dimensional space. They illustrated that a designer has a freedom to move in that plane which represents the current state of the art by trading an increase in one parameter for a decrease in others. Multiple linear regression is used to find this plane (Martino, 1993). 
The planar technology frontier approach with multiple linear regression is a reasonable tool to develop a long-term forecast for the performance of a technology or a device (Martino, 1993). This approach is used in this study to represent state of the art and heterogeneous characteristics of wireless mobile communication technologies with possible trade-off relationships among technical parameters. Another reason for using this approach instead of growth curves such as Fisher-Pry is that the technical upper limit of wireless communication - data capacity - is not known at this time.

Recent mobile phones include various services which were not available in the past generations such as email, World Wide Web, music or movies. Lee (2006) defined four categories to evaluate performance of wireless mobile communication technologies such as voice quality, data quality, picture/vision quality and service quality. Voice quality is generally measured subjectively. Three metrics, Circuit Merits (CM), Mean Opinion Score (MOS) and Diagnostic Rhyme Test (DRT), are used to measure voice quality. Data quality can be measured by bit error rate, chip error rate, symbol error rate, and frame error rate. Picture/vision quality can be understood by six metrics such as color acuity, depth perception, flicker perception, motion perception, noise perception, and visual acuity. Finally, service quality consists of three factors: coverage, required grade of service, and number of dropped calls. This factor has a trade-off with respect to the transmission power and cost. These performance factors help us to evaluate overall performance of wireless mobile communication technologies. Recent research (Ryu et al., 2004) exploring wireless mobile communication technologies used similar factors.

While these functional metrics can help us to evaluate the technologies, they are limited in assessing future feasibility. Generally, technology forecasts using these functional parameters or performance measures are more proper for the purpose of market planning while technological parameters are more appropriate for a forecast when R\&D planning is required (Martino, 1993).

A technological framework for wireless mobile communication technologies including key technological parameters can help us to forecast feasibility of B3G technologies. The current wireless radio communication systems consist of several kinds of wireless devices such as simple cordless phones, mobile cellular systems and personal communication systems. These 
different radio communication systems share some common characteristics. The fundamental objective of wireless communication systems is to provide communication channels between a mobile radio station and a radio port or base station which connects users to the fixed network infrastructure through the electromagnetic waves. Therefore, one important goal of mobile radio technology is to provide basic telephone service to more users with limited electromagnetic waves (Goodman, 1991).

The major design factors can be capacity, cost of implementation, and quality of service (Gibson, 1996). The capacity of wireless systems is closely related to frequency usage. The frequency spectrum on which wireless communication equipment depends is a limited natural resource. A major problem of the radio communication system is the limited availability of radio-frequency spectrum due to high demand. Therefore, the ideal mobile system can be defined by a system operating within a limited assigned frequency band and serving almost unlimited number of users (Lee, 2006).

The higher capacity can be achieved through advanced transmission techniques with efficient speech coding, error correcting channel codes, and bandwidth efficient modulation (Goodman, 1991). Key technology parameters regarding this capacity include the channel bandwidth, information compression, variable bit-rate control, improved channel assignment algorithms, and selection of multiple access schemes (Garg and Garg, 2001). These five factors should be considered in a forecasting model directly or indirectly.

The most common composite measure of the capacity is spectral efficiency. A good measure of spectral efficiency helps one to estimate the capacity of a mobile communications system and allows one to set up a minimum standard as a measure of reference (Garg and Garg, 2001). Therefore, the metrics used to measure spectral efficiency can also provide performance features of a wireless mobile communication technology, and hence good technical parameters for our forecasting model. Spectral efficiency can be defined as follows (Garg and Wilkes, 1996):

$$
\text { Spectral Efficiency }\left(\text { Erlangs } / \mathrm{MHz} / \mathrm{km}^{2}\right)=\frac{\text { Total number of channels availablein the system }}{\text { (Bandwidth)(Total coverage area })}
$$

Number of channels and channel bandwidth are also important technical parameters for wireless 
communication technologies. The total coverage area is excluded in this study because this factor is difficult to measure consistently across generations and is frequently specific to the particular implementation of carriers. In addition, other important technical parameters, channel bit rate, and data capacity, are considered in the model as they are important design parameters measuring performance of wireless communication technology which are not explicitly included in the spectral efficiency formula.

Table 3 Definition of key technical parameters identified

\begin{tabular}{|l|l|c|}
\hline \multicolumn{1}{|c|}{ Parameter } & \multicolumn{1}{|c|}{ Definition } & Metrics \\
\hline $\begin{array}{l}\text { Channel } \\
\text { bandwidth }\end{array}$ & $\begin{array}{l}\text { Channel bandwidth, channel spacing, RF channel spacing or bandwidth } \\
\text { per channel is size of radio frequency per each channel. }\end{array}$ & $\mathrm{kHz}$ \\
\hline $\begin{array}{l}\text { Number of } \\
\text { channels }\end{array}$ & $\begin{array}{l}\text { Number of channels is the number of pairs of radio frequencies meaning } \\
\text { a communications path between two computers or devices. }\end{array}$ & Number \\
\hline Channel bit rate & $\begin{array}{l}\text { The channel bit rate is the channel transmission bit rate for digitally } \\
\text { modulating the carrier and is also called the "transmission rate" or } \\
\text { "symbol rate/chip rate". This is the maximum theoretical digital bit rate } \\
\text { that can be produced through the network medium by the utilized } \\
\text { technology. }\end{array}$ & $\mathrm{kbps}$ \\
\hline Data capacity & $\begin{array}{l}\text { Data capacity is the actual throughput bit rate for the data (payload) that } \\
\text { is being passed through the system. }\end{array}$ & $\mathrm{kbps}$ \\
\hline
\end{tabular}

Throughout the study a panel of experts in the wireless industry was consulted. The panel members were technical experts from US and Korean institutes. They have confirmed the four technical parameters are important in the design of wireless communication technologies.

The detailed definitions of four parameters which are identified in this study are provided in Table 3. These parameters will be discussed along with their trends and trade-offs relation, and some of them will be selected for the forecasting model at the following section.

The multicollinearity is critical issue especially when regression is used to understand relation among independent variables and impact of each independent variable to the dependent variable. However, the use of regression for forecasting has typically been considered to be relatively robust to these problems when the some tradeoffs are expected to continue as in the past (Farrar and Glauber, 1967; Belsley, 1982; Belsley, 1987).

Since the purpose of this study is to forecast year of the first commercialization of B3G mobile communication technologies but not to investigate the relationships among independent variables nor degree of influences of them to dependent variable, the emphasis is on how well the model 
forecast when new technologies will be commercialized. However, basic test for possible multicollinearity should be done to check if it harms structural estimation for the estimated period. In this study, three indicators are used to check multicollinearity; VIF, Condition Index, and "perverse sign" of coefficients. If VIF is more than 10 or Condition Index more than 30, collinearity exists.

Channel Bandwidth and Number of Channels are expected to have strong linear relationship as technically number of channels is calculated by channel bandwidth and total bandwidth used by a technology and cause collinearity. The result of collinearity diagnostics also shows that Number of Channels causes collinearity and harm regression structure. Therefore, Number of Channels is excluded from the forecasting model in order to avoid violation of the assumptions of linear regression. The detail result of collineairty diagnostics is discussed at the analysis section.

This study suggests that four technical parameters are important to understand the state of the art of wireless communication technologies. However, if any technical parameter causes collinearity and harm regression structure, the forecasting based on the model could be wrong. Therefore, we examine collinearity by three indicators, VIF, Condition Index, and perverse sign of coefficients. The result is summarized in Table 4.

Table 4 Result of collinearity diagnostics

\begin{tabular}{|c|c|c|c|c|}
\hline \multirow{2}{*}{ Criteria } & \multicolumn{2}{|c|}{ 3G Forecasting Model } & \multicolumn{2}{c|}{ B3G Forecasting Model } \\
\cline { 2 - 5 } & $\begin{array}{c}4 \text { variables } \\
\text { (CBR, NOC, CBR, DCP) }\end{array}$ & $\begin{array}{c}3 \text { variables } \\
\text { (CBR, CBR, DCP) }\end{array}$ & $\begin{array}{c}4 \text { variables } \\
\text { (CBR, NOC, CBR, DCP) }\end{array}$ & $\begin{array}{c}3 \text { variables } \\
\text { (CBR, CBR, DCP) }\end{array}$ \\
\hline VIF & All less than 10 & All less than 10 & $13(\mathrm{CBW}), 11(\mathrm{CBR})$ & All less than 10 \\
\hline Condition Index & 36 (5 $^{\text {th }}$ Dimension $)$ & All less than 30 & $36\left(5^{\text {th }}\right.$ Dimension $)$ & All less than 30 \\
\hline Perverse Sign & Yes $(\mathrm{CBW})$ & No Perverse Sign & Yes $(\mathrm{CBW})$ & No Perverse Sign \\
\hline Result & Collinearity & No Collinearity & Collinearity & No Collinearity \\
\hline
\end{tabular}

Number of Channels is expected to cause collinearity because of its inherent relation with Channel Bandwidth. The result consists with the expectation. The Condition Index of multiregression model with four variables presents that the collinearity exists. The perverse sign of the coefficient of Channel Bandwidth indicates the collinearity harm the regression structure. Also, the same problem is found at the B3G model with four variables. If the variable, Number of 
Channels, is excluded, the two multi-regression models doesn't have any problem caused by collinearity.

Therefore, the model for forecasting wireless mobile communication technologies using a composite measure is defined as following with three variables;

$Y=b_{1} \times X_{C B W}+b_{2} \times X_{C B R}+b_{3} \times X_{\mathrm{DCP}}+b_{0}$

$Y$ : The year of first commercialization of a wireless communication technology

$X_{C B W}$ : Channel bandwidth

$b_{1}$ : Regression coefficient of channel bandwidth

$b_{2}$ : Regression coefficient of channel bit rate

$b_{3}$ : Regression coefficient of data capacity

$X_{C B R}$ : Channel bit rate

$X_{D C P}$ : Data capacity

$b_{0}$ : Constant

Using multiple linear regression for forecasting has a long history (Merz et al., 1972; Alexander and Nelson, 1973; Rohatgi and Weiss, 1977; Hutzler et al., 1985) and raises obvious questions about multicollinearity (Farrar and Glauber, 1967; Fujii and Mak, 1981; Askin, 1982; Belsley, 1982; Belsley, 1984; Belsley, 1987). The potential for tradeoffs among independent variables is a violation of the independences assumption among independent variables when regression method is used.

Data for the three parameters and year of first commercialization of 21 wireless mobile communication technologies from 1G to 3G were gathered from secondary data sources (Garg and Wilkes, 1996; Gibson, 1996; Lee, 2006; Smith and Collins, 2007). Since some sources use different metrics and concepts for the parameters, Validation was done by comparing the information with multiple sources and through informal interviews with members of our expert panel. The final data set used in this study is provided at the Table 5 . 
Table 5 Data used for the forecasting model

\begin{tabular}{|c|c|c|c|c|c|c|}
\hline & Technology & Generation & $\begin{array}{c}\text { Year of the } \\
\text { first } \\
\text { Adoption }\end{array}$ & $\begin{array}{c}\text { Channel } \\
\text { Bandwidth } \\
\text { [CBY. kHz] }\end{array}$ & $\begin{array}{c}\text { Channel Bit } \\
\text { Rate } \\
\text { [CBR, kbps] }\end{array}$ & $\begin{array}{c}\text { Data } \\
\text { Capacity } \\
\text { [DCP. kbps] }\end{array}$ \\
\hline NTT & Nippon Telegraph \& Telephone & $1 \mathrm{G}$ & 1979 & 25 & 0.3 & 0.3 \\
\hline NMT-450 & Nordic Mobile Telephone 450 & $1 \mathrm{G}$ & 1981 & 25 & 1.2 & 1.2 \\
\hline AMPS & Advanced Mobile Phone Service & $1 \mathrm{G}$ & 1983 & 30 & 10.0 & 10.0 \\
\hline C-Netz & $\begin{array}{l}\text { The Radio Telephone Network C utilizing } \\
\text { C450 standard }\end{array}$ & $1 G$ & 1985 & 20 & 5.3 & 5.3 \\
\hline TACS & Total Access Communications System & $1 \mathrm{G}$ & 1985 & 25 & 8.0 & 8.0 \\
\hline NMT-900 & Nordic Mobile Telephone 900 & $1 \mathrm{G}$ & 1986 & 12.5 & 1.2 & 1.2 \\
\hline D-AMPS & Digital AMPS (D-AMPS, IS-54, or TDMA) & $2 \mathrm{G}$ & 1990 & 30 & 48.6 & 9.6 \\
\hline GSM 900 & $\begin{array}{l}\text { Global System for Mobile } \\
\text { communications with } 900 \mathrm{MHz}\end{array}$ & $2 \mathrm{G}$ & 1990 & 200 & 270.8 & 14.4 \\
\hline CT2 & $\begin{array}{l}\text { A digital FDMA system that uses Time } \\
\text { Division Duplexing technology }\end{array}$ & $2 \mathrm{G}$ & 1991 & 100 & 72.0 & 19.2 \\
\hline CDMA One & $\begin{array}{l}\text { Code Division Multiple Access (CDMA } \\
\text { One or IS-95) }\end{array}$ & $2 \mathrm{G}$ & 1993 & 1250 & 1228.8 & 14.4 \\
\hline JDC & Japanese Digital Cellular System & $2 \mathrm{G}$ & 1993 & 25 & 42.0 & 14.0 \\
\hline GSM1800 & Digital Cellular System 1800 & $2 \mathrm{G}$ & 1993 & 200 & 270.8 & 9.6 \\
\hline iDEN & Integrated Digital Enhanced Network & $2 \mathrm{G}$ & 1994 & 25 & 64.0 & 9.6 \\
\hline cdma2000 & CVDMA.2000 1XRTT & $2.5 \mathrm{G}$ & 2001 & 1250 & 1228.8 & 153.0 \\
\hline GPRS & General Packet Radio Service & $2.5 \mathrm{G}$ & 2001 & 200 & 270.8 & 128.0 \\
\hline EDGE & Enhanced Data rates for GSM Evolution & $2.7 \mathrm{G}$ & 2002 & 200 & 812.5 & 384.0 \\
\hline $\begin{array}{l}\text { CDMA } \\
\text { EYDOO }\end{array}$ & $\begin{array}{l}\text { CDMA, } 2000 \text { Evolution-Data Optimized or } \\
\text { Evolution-Data only }\end{array}$ & $3 G$ & 2002 & 1250 & 1228.8 & 384.0 \\
\hline УСDMA & Wideband Code Division Multiple Access & $3 G$ & 2004 & 5000 & 5760.0 & 384.0 \\
\hline TD-SCDMA & $\begin{array}{l}\text { Time Division-Synchronous Code Division } \\
\text { Multiple Access }\end{array}$ & $3 G$ & 2006 & 1600 & 3300.0 & 384.0 \\
\hline TD-CDMA & $\begin{array}{l}\text { The primary air interface used by UMTS- } \\
\text { TDD }\end{array}$ & $3 G$ & 2006 & 5000 & 3300.0 & 384.0 \\
\hline HSDPA & High-Speed Downlink Packet Access & $3 G$ & 2006 & 5000 & 960.0 & 14400.0 \\
\hline
\end{tabular}

The data of 21 technologies are divided into two sections to validate the forecasting model. The first part consists of $1 \mathrm{G}$ to $2.7 \mathrm{G}$. The second part of $3 \mathrm{G}$ will be used to evaluate if the forecasting model based on the first data set is valid. Then, the whole 21 data set will be used to build the forecasting model for B3G wireless technologies. 


\section{Results}

Each trend of the three technical parameters of 21 technologies is examined using simple regression. The original data and logarithmically transformed data are compared to find which one is proper for the multi-regression model in the Table 6. The result shows that logtransformed data of all three variables have better $\mathrm{R}^{2}$ and $\mathrm{p}$-values. This supports that each technical parameter is growing exponentially rather than linearly. Therefore, logarithmically transformed data of three variables are used for the forecasting model.

Table 6 Linear and exponential regression models

\begin{tabular}{|c|c|c|c|c|}
\hline \multirow{2}{*}{ variable } & \multicolumn{2}{|c|}{ Original data } & \multicolumn{2}{c|}{ Logarithm transformed data } \\
\cline { 2 - 5 } & $\mathrm{R}^{2}$ & $\mathrm{p}$-value & $\mathrm{R}^{2}$ & $\mathrm{p}$-value \\
\hline$X_{C B W}$ & 0.472 & 0.001 & 0.723 & 0.000 \\
\hline$X_{C B R}$ & 0.446 & 0.001 & 0.839 & 0.000 \\
\hline$X_{D C P}$ & 0.128 & 0.112 & 0.849 & 0.000 \\
\hline
\end{tabular}

\section{Validation: Forecasting 3G technologies}

Table 7 presents the results of the multi-regression analysis of the proposed model with three variables. The first data set of sixteen technologies from $1 \mathrm{G}$ to $2.7 \mathrm{G}$ is used.

Table 7 The result of multi-regression for the $3 G$ forecasting model

\begin{tabular}{|c|c|c|c|c|c|c|}
\hline \multirow[b]{2}{*}{ Model } & & \multicolumn{2}{|c|}{$\begin{array}{c}\text { Unstandardized } \\
\text { Coefficients }\end{array}$} & \multirow{2}{*}{$\begin{array}{c}\begin{array}{c}\text { Standardized } \\
\text { Coefficients }\end{array} \\
\text { Beta } \\
\end{array}$} & \multirow[b]{2}{*}{$t$} & \multirow[b]{2}{*}{ Sig. } \\
\hline & & $B$ & Std, Error & & & \\
\hline & (Constant) & 1982,094 & 2.946 & & 672.801 & .000 \\
\hline & LNCBW & -.338 & 1.026 & -.070 & -.329 & .748 \\
\hline & LNCBR & 1.230 & .870 & .454 & 1.413 & .183 \\
\hline & LNDCP & 2,169 & .873 & .560 & 2.484 & .029 \\
\hline
\end{tabular}

a. Dependent Variable: VEAR 
The following forecasting model is used to fit to the second data set of 3G wireless mobile communication technologies and validate the extrapolation method. R-square of this model is 0.857 and p-value is 0.000 . Therefore, this model can explain $86 \%$ of the 16 technologies with three technical parameters.

$Y=-0.338 \times X_{L N C B W}+1.23 \times X_{L N C B R}+2.169 \times X_{L N D C P}+1982.094$

$Y$ : The year of first commercialization of a technology

$X_{\text {LNCBW }}:$ Log transformed channel bandwidth

$X_{L N C B R}:$ Log transformed channel bit rate

$X_{L N D C P}:$ Log transformed data capacity

The actual year of commercialization and forecasted year of wireless mobile communication technologies from $1 \mathrm{G}$ to $2.7 \mathrm{G}$ were compared. Figure 2 graphically shows how forecasted years are close to the actual year of commercialization during the period from 1979 to 2002 . The $\mathrm{x}$-axis and y-axis plot actual year and forecasted year of commercialization of a technology respectively. The ideal forecasting model will arrange all technologies along with the diagonal line. The technologies plotted above the line means that they are launched in the market earlier than the model forecasted. The graph also shows that while the $1 \mathrm{G}$ and $2 \mathrm{G}$ technologies are scattered on the line, all 2.5 and 2.7G technologies are located below the line. This implies that these technologies (2.5 and 2.7G) are commercialized late comparing the overall trend of the technological trajectory. 


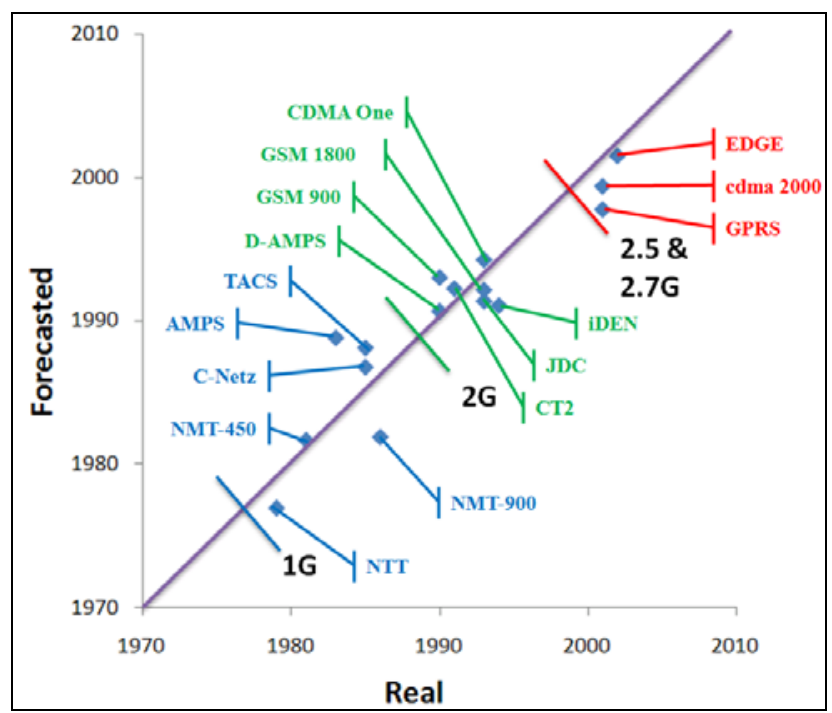

Figure 2 Comparing the real and forecasted year of wireless mobile communication technologies from 1G to 2.7G

Then, the model is used to forecast 3G technologies which already have been commercialized. The forecasted year of $3 \mathrm{G}$ technologies and actual year of the first adoption are compared in the Figure 3. All 3G technologies except for HSDPA are located below the line which means that they took longer time until they were launched considering the trend of commercialization of technologies from $1 \mathrm{G}$ to $2.7 \mathrm{G}$.

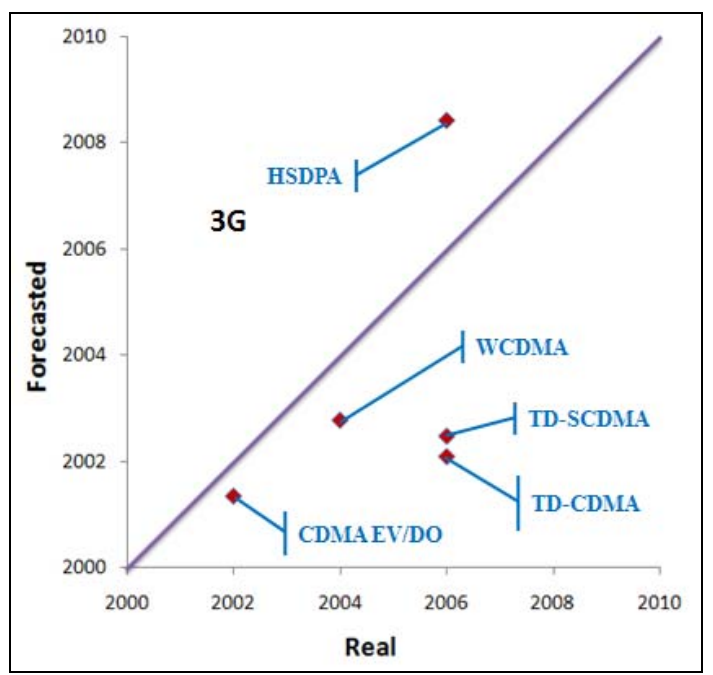

Figure 3 Comparing the real and forecasted year of $3 G$ wireless mobile communication technologies 
In Figure 3, TD-SCDMA and TD-CDMA show a relatively large gap between the forecasted and real year of the first commercialization. This comes from a unique situation regarding why these technologies had been developed. TD-SCDMA and TD-CDMA were developed by the Chinese Wireless Technology Standard Group to protect and improve the national technological competency and market and late entrants in the market (Edwards, 2003; Zheng et al., 2005). The Table 8 summarized the result.

Table 8 Forecasted year of 3G technologies

\begin{tabular}{|c|c|c|}
\hline 3G Technologies & Actual Year & Forecasted Year \\
\hline CDMA EV/DO & 2002 & 2001 \\
\hline WCDMA & 2004 & 2003 \\
\hline TD-SCDMA & 2006 & 2003 \\
\hline TD-CDMA & 2006 & 2002 \\
\hline HSDPA & 2006 & 2008 \\
\hline
\end{tabular}

The Mean Absolute Error (MAE) of the result is 2.2 years. If two Chinese technologies are excluded, the MAE is 1.3 year. A statistic test is used to validate further whether the forecasting model is appropriate for the estimation of the year of first commercialization of five 3G technologies. Since the number of data is less than thirty and doesn't follow a normal distribution, the Wilcoxon Signed-Rank test is used. The result provided in the Table 9 shows that there is not a statistically significant difference between the actual and predicted years. Therefore, it can be concluded that the forecasting model using multi-regression is statistically significant and can be used to forecast the next generation of wireless mobile communication technologies (4G.). However further technology development may alter this model. Periodic review of what the model predicts in the future would help to validate the model. 
Table 9 Result of Wilcoxon Signed-Rank test of real and forecasted years of $3 G$ technologies

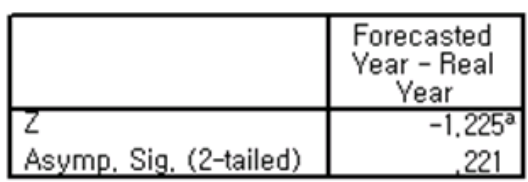

a. Based on positive ranks.

b. Wilcoxon Signed Ranks Test

\section{Forecasting B3G Technologies}

The whole data sets from $1 \mathrm{G}$ to $3 \mathrm{G}$ of 21 wireless mobile communication technologies are used to build the forecasting model for B3G technologies. The regression results with the three parameters are provided in Table 10. R-square of this model is 0.915 and P-value is 0.000 .

Table 10 Result of regression with three variables to forecast B3G

\begin{tabular}{|c|c|c|c|c|c|c|}
\hline \multirow{2}{*}{\multicolumn{2}{|c|}{ Model }} & \multicolumn{2}{|c|}{$\begin{array}{c}\text { Unstandardized } \\
\text { Coefficients }\end{array}$} & \multirow{2}{*}{$\begin{array}{c}\begin{array}{c}\text { Standardized } \\
\text { Coefficients }\end{array} \\
\text { Beta }\end{array}$} & \multirow[b]{2}{*}{$t$} & \multirow[b]{2}{*}{ Sig. } \\
\hline & & $B$ & Std, Error & & & \\
\hline & (Constant) & 1981.180 & 1.894 & & 1046,114 & .000 \\
\hline & LNCBW & -.114 & .681 & -.027 & -.167 & .869 \\
\hline & LNCBR & 1.515 & .510 & .498 & 2.973 & .009 \\
\hline & LNDCP & 1.808 & 486 & 523 & 3.720 & 002 \\
\hline
\end{tabular}

a. Dependent Variable: YEAR

Finally, the forecasting model for a B3G wireless mobile communication technology is proposed as follows.

$Y=-0.114 \times X_{L N C B W}+1.515 \times X_{L N C B R}+1.808 \times X_{L N D C P}+1981.180$

The regression coefficient data capacity has the highest value and statistically significant. This implies that data capacity has higher influence to the technological change. Wireless mobile communication technologies have been developed in a way to provide various multimedia services to more people given a constant broadband. Therefore, data capacity could be 
considered as the most important indicator of technical improvement (Hata, 1999; Sun et al., 2001; Hu and Lu, 2003; Ryu et al., 2004).

The coefficient of Chanel Bandwidth has a negative sign in both 3G and B3G forecasting models. This is consistent with the technical characteristic of Channel Bandwidth. This could be considered as input of two throughput variables, Channel Bitrate and Data Capacity. Given same channel bitrate and data capacity, a more developed technology would use less bandwidth. Therefore, the coefficient of this variable can be negative.

\section{Case of Forecasting $4^{\text {th }}$ Generation (4G) Technologies}

An example is provided below to demonstrate how the forecasting model can be used to overlook the features of the future technologies. Since there is not a specification for $4 \mathrm{G}$ technologies available yet, a possible 4G technology is defined based on the available literature (Table 11) at the Table 12.

Table 11 Suggested specification of 4G

\begin{tabular}{|l|l|l|l|}
\hline & Sun et al. (2001) & Ryu et al. (2005) & Hu and Lu (2003) \\
\hline Starting year & $2010-2012$ & 2005 (test) & $2005-2020$ \\
\hline Spectrum & $3 \mathrm{GHz}-5 \mathrm{GHz}$ & $3 \mathrm{GHz}-5 \mathrm{GHz}$ & $2 \mathrm{GH}-5 \mathrm{GHz}$ \\
\hline Bandwidth & $10 \mathrm{MHz}-20 \mathrm{MHz}$ & $5 \mathrm{MHz}-20 \mathrm{MHz}$ & - \\
\hline Transmission rate & - & $100 \mathrm{Mbps}$ & $100 \mathrm{Mbps}$ \\
\hline Multiplexing & FDMA, TDMA, CDMA & $\begin{array}{l}\text { OFDM-FDMA, FDD, } \\
\text { frequency-hopping }\end{array}$ & OFDM, HDR \\
\hline $\begin{array}{l}\text { Driven } \\
\text { Technology }\end{array}$ & $\begin{array}{l}\text { Intelligent software, Auto } \\
\text { configuration }\end{array}$ & $\begin{array}{l}\text { Open wireless } \\
\text { architecture, AMC }\end{array}$ \\
\hline
\end{tabular}


Table 12 Specifications of the Virtual 4G used for forecasting

\begin{tabular}{|c|c|c|c|c|}
\hline & $\begin{array}{c}\text { Year of first } \\
\text { commercialization }\end{array}$ & $\begin{array}{c}\text { Channel } \\
\text { Bandwidth } \\
\text { (CBW) }\end{array}$ & $\begin{array}{c}\text { Channel } \\
\text { Bitrate } \\
\text { (CBR) }\end{array}$ & $\begin{array}{c}\text { Data Capacity } \\
\text { (DCP) }\end{array}$ \\
\hline $\begin{array}{c}4 \mathrm{G} \\
\text { (virtual) }\end{array}$ & Unknown & $20 \mathrm{MHZ}^{1}$ & $10 \mathrm{Mbps}^{2}$ & $100 \mathrm{Mbps}^{3}$ \\
\hline
\end{tabular}

1. Channel Bandwidth of 20MHZ is used as suggested by Sun et al. (2001) and Ryu et al. (2005)

2. Number of Channels and Channel Bitrate are assumed based on the previous technologies.

3. Data Capacity of 100Mbps is used as suggested by Ryu et al. (2005) and Hu and Lu (2003).

The forecasted year of the first commercialization of the target technology

$=-0.11 \times 9.90+1.52 \times 9.21+1.81 \times 11.51+1981.18$

$=2015$

According to the forecasting model, the virtual $4 \mathrm{G}$ technology which can fully support data capacity of $100 \mathrm{Mbps}$ is expected to be commercially available in 2015. The result is closer to the year foresighted by Hu and Lu (2003).

Wireless carriers may deploy various technologies with lower data capacity than full 4G technology until market growth and infrastructure for the new generation are ready. Therefore, a sensitivity analysis using different performance scenarios on each parameter can provide better insight into the possible future of wireless technologies. Figure 4 shows how the time to market of $4 \mathrm{G}$ changes along with the data capacity used in the forecasting model. If $4 \mathrm{G}$ with the data capacity of $20 \mathrm{Mbs}$ is launched, the model forecasts that it will be commercialized in 2012. Therefore, depending on the actual data capacity of 4G, launching time of the technology could range from 2012 to 2015. 


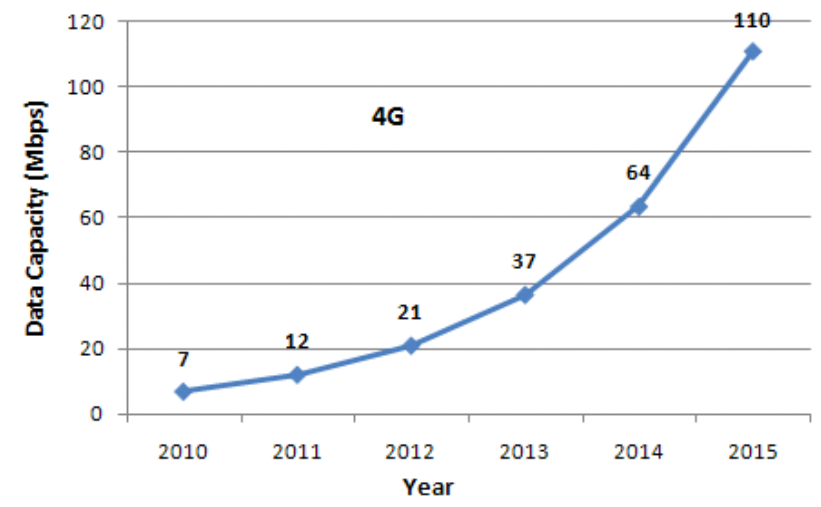

Figure 4 Sensitivity analysis with different data capacity (DCP)

Before the second generation was fully serviced, the migration technologies called 2.5G and 2.7G had been deployed. The migration stage of wireless mobile communication technologies provides benefits of extending the previous infrastructure and fast adoption of a new generation. The sensitivity analysis shows when 3.5G (migration between 3G and 4G) and 4G technologies will be available in the market in Table 13.

Table 13 Forecasting result of 4G

\begin{tabular}{|c|c|c|c|c|}
\hline \multirow{2}{*}{ Technology } & $\begin{array}{c}\text { Channel } \\
\text { Bandwidth } \\
\text { (CBW, MHz) }\end{array}$ & $\begin{array}{c}\text { Channel bit rate } \\
\text { (CBR, Mbps) }\end{array}$ & $\begin{array}{c}\text { Data Capacity } \\
\text { (DCP, Mbps) }\end{array}$ & $\begin{array}{c}\text { Forecasted } \\
\text { Year }\end{array}$ \\
\hline \multirow{2}{*}{$\begin{array}{c}\text { Migration } \\
(3.5 G)\end{array}$} & 20 & 5 & 10 & 2010 \\
\cline { 2 - 5 } & 20 & 5 & 30 & 2012 \\
\hline \multirow{2}{*}{$4 G$} & 20 & 5 & 50 & 2013 \\
\cline { 2 - 5 } & 20 & 10 & 20 & 2012 \\
\hline
\end{tabular}

All technological trajectories from $1 \mathrm{G}$ to $4 \mathrm{G}$ are illustrated in Figure 5. Two interesting facts are found in the trajectories. A new generation was introduced in the market every 11 years later after the first introduction of previous technology generation, and this is expected to continue at the 4th Generation. In other words, each generation from $1 \mathrm{G}$ to $3 \mathrm{G}$ has been used 11 years until a new generation. However, the time-lag between two generations has been increased by three 
years. The gap between $1 \mathrm{G}$ and $2 \mathrm{G}$ is 4 years, and $2 \mathrm{G}$ and $2.5 \mathrm{G}$ which is migration for $3 \mathrm{G} 7$ years. The model forecasted that $4 \mathrm{G}$ will be introduced 10 years later after the last technology of 3G. This may happen because of technical difficulty to develop further generation and effort for standardization.

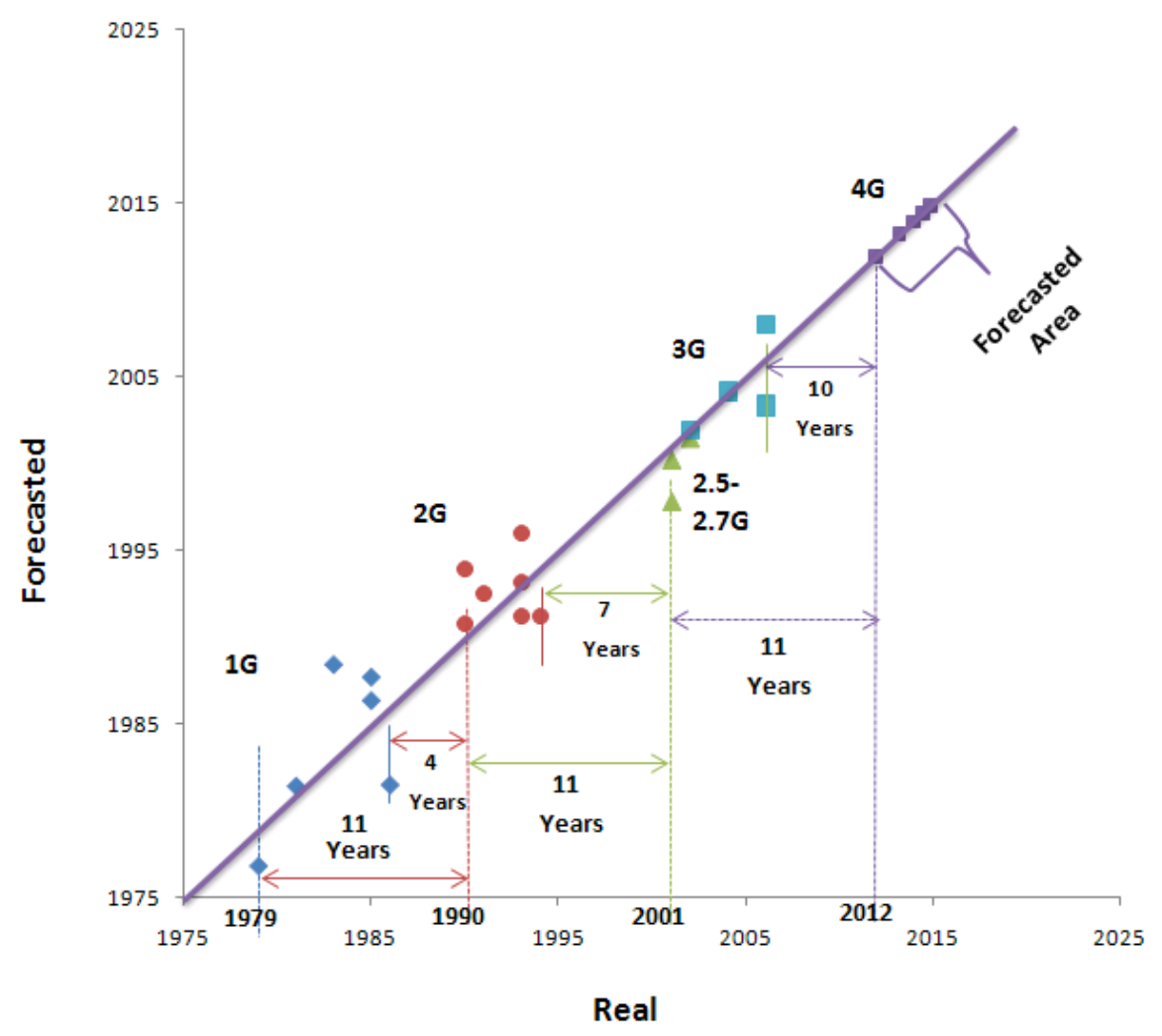

Figure 5 Technology trajectories from 1G to 4G

This result is consistent with the technological trends of wireless communications and the market needs. Since the first wireless phone introduced in the market, various technologies and standards competed in the second generation of wireless technologies. However, as customers' needs for seamless connection and ubiquitous communication worldwide increased, standardization and convergence of multiple technologies became critical in developing next generation technologies. Therefore, it is expected that only a few $4 \mathrm{G}$ technologies will be developed.

Two interesting facts were found from the technology trajectories. A new generation including 
migration stage of wireless mobile communication technology had been established in the market in every 11 years. Another finding was the increasing time-lag between the end of the old generation and the beginning of the new generation. Digital AMPS (D-AMPS), the first 2G technology, was commercialized four years later after the last $1 \mathrm{G}$ technology, Nordic Mobile Telephone 900 (NMT-900), was introduced in 1986. The migration generation of the third technologies (2.5G), cdma2000 and GPRS, took seven years to reach to the market after the last $2 \mathrm{G}$ technology. The model forecasted this trend will be continued at $4 \mathrm{G}$.

\section{Conclusions}

The wireless communication market has been skyrocketing for 25 years since its first introduction, and as a result wireless communication technology is one of the fast innovating technologies. This study provides a better understanding of both those technologies and markets by reviewing past and current technologies and predicting future technologies. For this purpose, five steps of forecasting B3G technologies are suggested as followings.

Step 1: define technology structure and parameters

A technology structure and a forecasting model for the fourth generation wireless mobile communication technology (4G) with three technical parameters -- channel bandwidth, channel bit rate, and data capacity -- are introduced.

Step 2: describe foreseeable technologies

The twenty one wireless technologies from 1G to 3G which has been commercialized are identified with their technical specifications. Also, possible features of the $4^{\text {th }}$ Generation wireless technology are suggested based on literature review. The data capacity of the technology is expected to reach $100 \mathrm{Mbps}$.

Step 3: model the evolution of technologies 
Extrapolation method was used with the past data of 21 wireless technologies from 1G to 3G to build the forecasting model. The collinearity diagnostics was performed to check if there was any technical parameter caused collinearity and harm regression structure. Three criteria, VIF, Condition Index, and perverse sign, are used for this purpose.

Step 4: forecast the expected year of commercialization of B3G technologies

The model forecasted that the 4G technology supporting 100Mbps transmission will be commercialized in 2015. In addition to the forecast of the target technology, further sensitivity analysis was performed to understand when the first migration will be deployed and how the evolution of $4 \mathrm{G}$ technology will be proceeding in the future.

Step 5: provide and discuss a trajectory of future wireless mobile communication technologies The trajectory of 26 technologies including 5 expected B3G technologies was suggested by the forecasting model. The trajectory showed that the next generation had been launched in 11 years after the first introduction of the previous generation throughout all generations. The fourth generation technology is also expected to be commercialized in 11 years after the first migration technology of 3G, cdma2000 and GPRS in 2001.

There are also some limitations in this study. The model was built on three technical factors. Therefore, the forecasting result is vulnerable to the selection process for these factors. They were selected based on literature review and experts' opinion in this study. Patent or bibliometric analysis could be considered to make the forecasting model more robust.

Forecasting accuracy is dependent on how well the underlying assumption of a certain method is fit to the real data and model (Levary and Han, 1995). Trend extrapolation method was used to forecast wireless mobile communication technologies because the limit of the current technical approach was not well defined, the performance and operation of B3G were unknown, and a long-term forecast was required. The model assumes that performance of $4 \mathrm{G}$ technologies will increase exponentially. The model showed that the current and previous generations fit well to 
the exponential trend, but if $4 \mathrm{G}$ technologies do not follow this trend, the overall forecasting model will need to be modified with new data.

The study focused only on technical factors to forecast the future of wireless mobile communication technologies without detailed consideration of the markets, so the year of first commercialization was used to reflect market adoption indirectly into the model. However, market penetration and carrier's strategy for both current and future wireless mobile communication technologies need to be incorporated into the analysis in order to provide more comprehensive and accurate forecasting. Even though there are some limitations, this study provides a useful forecasting framework and an outlook for future wireless mobile communication technologies through a quantitative analysis.

\section{Notes on contributors}

Tugrul U Daim is an Associate Professor of Engineering and Technology Management at Portland State University. Dr Daim had been with Intel Corporation for over a decade before he joined PSU as a full time faculty. Dr Daim's research involves exploration of technology assessment in industries including automotive, energy, semiconductor manufacturing, communications and health care. He consults with government agencies and companies all around the world. He is also a visiting Professor at Technical University of Hamburg Harburg. Dr. Daim has over 100 papers published in journals and conference proceedings. He is the editor in chief for International Journal of Innovation and Technology Management. He has a PhD in Systems Science and Engineering Management and MS in Engineering Management from Portland State University, MS in Mechanical Engineering from Lehigh University and a BS in Mechanical Engineering from Bogazici University in Turkey.

Jisun Kim is a Ph.D. candidate at Engineering and Technology Management of Portland State University studying the efficiency and efficiency pattern of university technology commercialization. He received his B.S. in Industrial Engineering, M.S. in Industrial Engineering - R\&D Management System from SungKyunKwan University, and M.S. in Engineering Management from Portland State University. He is currently working for Bonneville Power Administration to develop a technology landscape of electricity storage technologies and 
build a technology roadmap of northwest regional energy efficiency roadmap. His research areas include technology forecasting, technology roadmapping, technology transfer, and R\&D management. His recent studies have been published in Technovation, Technology Analysis \& Strategy Management, International Journal of Innovation and Technology Management, and International Journal of Applied Management Science.

Dr. Timothy R. Anderson is an Associate Professor of Engineering and Technology Management at Portland State University. He received his M.S.I.E. and Ph.D. in Industrial Engineering from the Georgia Institute of Technology after receiving his Bachelor's in Electrical Engineering from the University of Minnesota. He has worked for and consulted with a variety of companies including Honeywell, Oki Electric, Menlo Logistics, and the U.S. Postal Service. He is currently Program Chair for PICMET '06 and the Director of Technical Activities for the Portland International Center for the Management of Engineering and Technology. Prior to this, he served as Program Co-Chair for PICMET '97 and Program Chair for PICMET '99, '01, '03, ’04, '05,'06, '07, '08 and '09. His current research interests are productivity analysis, operations research, service engineering, technology forecasting, and new product development. Recent journal articles have been published in the IEEE Transactions on Engineering Management, Technological Forecasting and Social Change, Technovation, and the Journal of Productivity Analysis. He is a fellow in the American Indian Science Engineering Society.

\section{References}

Alexander, A. J. and J. R. Nelson, "Measuring Technological Change: Aircraft Turbine Engines." Technological Forecasting and Social Change 5, 1973, pp. 189-203.

Askin, R. G., "Multicollinearity in Regression: Review Adn Examples." Journal of Forecasting 1, 1982, pp. 281-292.

Belsley, D. A., "Assessing the Presence of Harmful Collinearity and Other Forms of Weak Data through a Test for Signal-to-Noise." Journal of Econometrics 20(2), 1982, pp. 211-253.

Belsley, D. A., Demeaning Conditioning Diagnostics through Centering, American Statistical Association. 38, 1984, pp. 73-77. 
Belsley, D. A., [Collinearity and Least Squares Regression]: Comment: Well-Conditioned Collinearity Indices, Institute of Mathematical Statistics. 2, 1987, pp. 86-91.

Bi, Q. and G. I. Zysman, "Wireless Mobile Communications at the Start of the 21st Century." IEEE Communications Magazine 39(1), 2001, pp. 110.

Dasilva, J. S., D. Ikonomou and H. Erben, "European R\&D Programs on Third-Generation Mobile Communication Systems." Personal Communications, IEEE [see also IEEE Wireless Communications] 4(1), 1997, pp. 46-52.

Dongchun, S., K. Jinbae, R. Seungwan, O. Donsung, L. Joowan and K. Minhyung, Scenario Decomposition Based Analysis of Next Generation Mobile Services. The International Conference of Advanced Communication Technology, 2006, pp. 403-408.

Du Preez, G. T. and C. W. I. Pistorius, "Analyzing Technological Threats and Opportunities in Wireless Data Services." Technological Forecasting and Social Change 70(1), 2003, pp. 1-20.

Edwards, C., "The Evolution of Td-Scdma China Takes Its Pick." Communications Engineer 1(1), 2003, pp. 6-8.

Evci, C., U. Barth, P. Sehier and R. Sigle, The Path to Beyond 3g Systems: Strategic and Technological Challenges. International Conference on 3G Mobile Communication Technologies, 2003, pp. 299-303.

Evci, C. C., Future Trends for Mobile Communications in Europe. Mediterranean Electrotechnical Conference, 1994, pp. 133-136 vol.1.

Farrar, D. E. and R. R. Glauber, "Multicollinearity in Regression Analysis: The Problem Revisited." Review of Economics \& Statistics 49(1), 1967, pp. 92.

Flament, M., F. Gessler, F. Lagergren, O. Queseth, R. Stridh, M. Unbehaun, J. Wu and J. Zander, "Approach to 4th Generation Wireless Infrastructures - Scenarios and Key Research Issues." IEEE Vehicular Technology Conference 2, 1999, pp. 1742-1746.

Frank, L. D., "An Analysis of the Effect of the Economic Situation on Modeling and Forecasting the Diffusion of Wireless Communications in Finland." Technological Forecasting and Social Change 71(4), 2004, pp. 391-403.

Fujii, E. T. and J. Mak, "Forecasting Tourism Demand: Some Methodological Issues." Annals of Regional Science 15(2), 1981, pp. 72.

Garg, V. K. and V. K. Garg, Introduction to Wireless and Personal Communications. Piscataway, NJ, Institute of Electrical and Electronics Engineers, 2001.

Garg, V. K. and J. E. Wilkes, Wireless and Personal Communications Systems. Upper Saddle River, NJ, Prentice Hall PTR, 1996. 
Gazis, V., N. Houssos, A. Alonistioti and L. Merakos, Evolving Perspectives of 4th Generation Mobile Communication Systems, 2002, pp. 201-207 vol.1.

Gibson, J. D., The Mobile Communications Handbook. New York, IEEE Press, 1996.

Goodman, D. J., "Trends in Cellular and Cordless Communications." IEEE Communications Magazine 29(6), 1991, pp. 31-40.

Gruber, H., The Economics of Mobile Telecommunications. Cambridge ; New York, Cambridge University Press, 2005.

Hanson, W. H. and N. Ramani, Technology Forecasting: A Hydroelectric Company Experience, Miami, FL, USA, Inderscience Enterprises Ltd, Geneva, Switz, 1988, pp. 266-270.

Hata, M., Fourth Generation Mobile Communication Systems Beyond Imt-2000. Fifth AsiaPacific Conference on Communications, 1999, pp. 765-767 vol.1.

Hu, J. and W. W. Lu, Open Wireless Architecture - the Core to 4g Mobile Communications, 2003, pp. 1337-1342 vol.2.

Hutzler, W. P., J. R. Nelson, R. Y. Pei and C. M. Francisco, "Nonnuclear Air-to-Surface Ordnance for the Future: An Approach to Propulsion Technology Risk Assessment." Technological Forecasting and Social Change 27(2-3), 1985, pp. 197-227.

ITU, "World Telecommunication/Ict Development Report 2010." International Telecommunication Union (ITU), Geneva Switzerland, 2010, pp. 1-217.

Jorguseski, L., E. Fledderus, J. Farserotu and R. Prasad, "Radio Resource Allocation in Third Generation Mobile Communication Systems." Communications Magazine, IEEE 39(2), 2001, pp. 117-123.

Kim, Y. B., S. Y. Seo and Y.-T. Lee, A Substitution and Diffusion Model with Exogenous Impact: Forecasting of Imt-2000 Subscribers in Korea, 1999, pp. 948-952 vol.2.

Kumar, V., A. Nagpal and R. Venkatesan, "Forecasting Category Sales and Market Share for Wireless Telephone Subscribers: A Combined Approach." International Journal of Forecasting 18(4), 2002, pp. 583-603.

Lee, W. C. Y., Wireless and Cellular Telecommunications, McGraw-Hill, 2006.

Levary, R. R. and D. Han, "Choosing a Technological Forecasting Method." Industrial Management (Norcross, Georgia) 37(1), 1995, pp. 14-18.

Madden, G. and J. Tan, "Forecasting Telecommunications Data with Linear Models." Telecommunications Policy 31(1), 2007, pp. 31-44.

Martino, J. P., Technological Forecasting for Decision Making. New York, McGraw-Hill, 1993. 
Merz, P. H., L. J. Painter and P. R. Ryason, "Aerometric Data Analysis--Time Series Analysis and Forecast and an Atmospheric Smog Diagram." Atmospheric Environment (1967) 6(5), 1972, pp. 319-342.

Minomo, M. and T. Masamura, "Prospects for Mobile Communication Systems and Key Technologies Capable of Supporting Expanding Mobile Multimedia Services." Journal of Circuits, Systems and Computers 13(2), 2004, pp. 237-251.

Mohr, W. and R. Becher, Mobile Communications Beyond Third Generation. IEEE Vehicular Technology Conference, 2000, pp. 654-661 vol.2.

OECD, "Mobile Telecommunication Services Revenue in Total for Oecd." OECD Key ICT Indicators, 2009.

Ohmori, S., Y. Yamao and N. Nakajima, "The Future Generations of Mobile Communications Based on Broadband Access Technologies." IEEE Communications Magazine 38(12), 2000, pp. 134-142.

Padgett, J. E., C. G. Gunther and T. Hattori, "Overview of Wireless Personal Communications." Communications Magazine, IEEE 33(1), 1995, pp. 28-41.

Park, J., H. Lee and M. Kim, Technical Standardization Status and the Advanced Strategies of the Next Generation Mobile Communications. The 8th International Conference of Advanced Communication Technology, 2006, pp. 884-887.

Rohatgi, P. K. and C. Weiss, "Technology Forecasting for Commodity Projections: A Case Study on the Effect of Substitution by Aluminum on the Future Demand for Copper." Technological Forecasting and Social Change 11(1), 1977, pp. 25-48.

Ryu, S., D. Oh, G. Sihn, D. Kim and K. Han, The Next Generation Mobile Services and a Proposed Network Architecture. IEEE Vehicular Technology Conference, 2004, pp. 3306-3309 Vol. 5.

Seungwan, R., P. Sei Kwon, O. Donsung, S. Gyungchul, H. Kichul and H. Seungku, "Research Activities on Next-Generation Mobile Communications and Services in Korea." Communications Magazine, IEEE 43(9), 2005, pp. 122-131.

Smith, C. and D. Collins, 3g Wireless Networks. New York, McGraw-Hill, 2007.

Smyth, G. C., G. Brody and A. Javed, Wireless: Growth Engine for Advanced Global Telecommunications. MTT-S Symposium on Technologies for Wireless Applications Digest, 1995, pp. 7-11.

Sun, J.-Z., J. Sauvola and D. Howie, Features in Future: 4g Visions from a Technical Perspective. IEEE Global Telecommunications Conference, 2001, pp. 3533-3537 vol.6.

Venkatesan, R. and V. Kumar, "A Genetic Algorithms Approach to Growth Phase Forecasting of 
Wireless Subscribers." International Journal of Forecasting 18(4), 2002, pp. 625-646.

Wenrong, W., M. Xie and K. Tsui, Forecasting of Mobile Subscriptions in Asia Pacific Using Bass Diffusion Model. IEEE International Conference on Management of Innovation and Technology, 2006, pp. 300-303.

Yoo, S.-H. and H.-S. Moon, "An Estimation of the Future Demand for Portable Internet Service in Korea." Technological Forecasting and Social Change 73(5), 2006, pp. 575-587.

Zheng, K., L. Huang, W. Wang and G. Yang, "Td-Cdm-Ofdm: Evolution of Td-Scdma toward 4g " IEEE Communications Magazine 43(1), 2005, pp. 45-52. 